\title{
Response Evaluation Criteria in Solid Tumors Version 1.1
}

National Cancer Institute

\section{Source}

National Cancer Institute. Response Evaluation Criteria in Solid Tumors Version 1.1. NCI

Thesaurus. Code C124415.

A standardized guideline developed by the Response Evaluation Criteria in Solid Tumors (RECIST) Working Group in 2000 and revised in 2009, which is an objective response criteria used to assess solid tumor response and to measure change in tumor size for use in adult and pediatric cancer clinical trials. Major revisions in RECIST version 1.1 includes lymph node (LN) measurement, the maximum number of target lesions, the definition of disease progression, as well as the inclusion of and guidance on the use of MRI and FDG PET in the detection of new lesions. 